\title{
Investigating the Prevalence of High-Risk Behaviors among Professional Athletes
}

\author{
Ahmadali Asefi (iD ${ }^{1,}{ }^{*}$ and Ali Ghanbari Barzian ${ }^{2}$ \\ ${ }^{1}$ Department of Sport Sciences, University of Isfahan, Isfahan, IR Iran \\ ${ }^{2}$ Department of Social Sciences, University of Isfahan, Isfahan, IR Iran \\ "Corresponding author: Department of Sport Sciences, University of Isfahan, Isfahan, IR Iran. Tel: +98-3137934286, Email: aa.asefi@spr.ui.ac.ir
}

Received 2019 October 15; Revised 2020 September 06; Accepted 2020 September 07.

\begin{abstract}
The prevalence of high-risk behaviors among professional athletes as role models for their fans, especially adolescents and young people, is important to be considered. Thus, this study aimed to investigate the prevalence of HRBs in Iranian professional athletes. This cross-sectional study included 1,940 athletes that were active in eight popular sports from 12 cities of the country. Data were collected using stratified random sampling and a self-made high-risk behavior questionnaire. To analyze the data, descriptive statistical methods were used. The results showed the prevalence of doping among professional athletes was $3 \%$. Besides, $0.3 \%$ of the professional athletes on average smoke daily, and $2 \%$ used shisha (smoking water pipes) daily. Moreover, $2.5 \%$ of professional athletes drunk alcohol at least one time per month. Also, the prevalence of violence involvement among professional athletes was $4.1 \%$, and the prevalence of illicit drug use was $0.3 \%$. The research results showed all high-risk behaviors were prevalent to some degree among professional athletes.
\end{abstract}

Keywords: Behavior, Doping in Sports, Tobacco Products, Shisha (Smoking Water Pipes), Alcohol, Violence, Illicit Drugs

\section{Background}

Unhealthy and high-risk behaviors are important public health problems with both long- and short-term effects (1). Ford describes risky behavior as any behavior that increases negative health-related outcomes for the doer (2). Since the end of the 1980s, risky behaviors in the youth have become a major issue for public health (3). More attention has been recently paid to the role of sports in preventing (4) and controlling HRBs. Some studies showed sports programs were associated with decreases in some HRBs (4-6). Conversely, other studies showed that they were associated with increases in some HRBs $(3,4,7,8)$. These contradictions, along with the issue that these studies were often limited to educational contexts (e.g., high schools, colleges), and therefore failed to include sports participation in other settings (4), makes it necessary to do more research. In addition, it is not known that the frequency of HRBs in professional levels increases or decreases.

Several factors, such as gender differences, competition type, sports motivations, sports level, and sports type $(8,9)$, can influence the athlete's decision on the involvement in HRBs. While it seems that the sports level can affect the prevalence of HRBs, no research has studied the effect of sports level, especially in a sample of professional athletes. Professional athletes are often role models for adolescents and young adults, who often mimic their behaviors, including drug abuse (10). Today, professional athletes' behaviors due to media and social networks are more in the public's eye than before. Some professional athletes tend to use drugs to improve their performance, increase the chance of winning, do self-treat, and deal with stressors (11). Some of them may engage in risky behaviors such as drinking alcohol, tobacco use, and violence that threaten their health. In contrast, professional athletes are commonly characterized as being fit, strong, and healthy (12). Although professional athletes would receive medically supervised injections of hormones and other performanceenhancing drug regimens (10) to maintain their physical capacities and performance in sports, in some cases, because of winning at all costs and other reasons, some professional athletes engage in some HRBs such as doping (13). As professional athletes must serve as role models and spokesmen for drug-free sports and lifestyles (10), examining the prevalence of HRBs in professional athletes engaging in different sports is very important and may reveal optimal strategies for health professionals. According to Bovard (2008), it is important to look at the prevalence of risk 
behaviors in sports (2) and among athletes. As no research has examined the prevalence of HRBs in professional athletes, the primary purpose of our study was to examine the prevalence of HRBs in Iranian professional athletes.

\section{Objectives}

The study aimed to examine the prevalence of HRBs in Iranian professional athletes.

\section{Materials and Methods}

We conducted a cross-sectional survey study on 1,940 Iranian male professional athletes in eight sports. The professional athletes aged 17 to 29 years $(M=25.7)$ of Olympic medalists, World Championships medalists, members of national teams, and national champions, and athletes involved in the Premier League in sports such as Soccer, Basketball, Volleyball, Handball, Karate, Wrestling, Weightlifting, and Taekwondo were selected by stratified random sampling as the study sample. The sample was selected according to the number of athletes in each sport. The study instrument captured the data of professional athletes based on responses to questions on six so-called highrisk behaviors, including Doping: the frequency of illicit performance-enhancing drugs use at least once during the last 12 months; Cigarette use: the average number of cigarettes smoked per day; Shisha (smoking water pipes) use: the average frequency of shisha use per day; Alcohol use: drinking alcohol at least one time per month. Violence involvement: the frequency of fighting with spectators, coaches, referees, opponents, teammates, and other people per season; and Illicit drug use: the frequency of cocaine, heroin, cannabis, and new psychoactive substances used in the last 12 months. The face and content validity of the survey instrument were investigated with the exact following of study literature and comments of experts (10 people), and its reliability was calculated by the Cranach's alpha coefficient $(\alpha=0.81)$. Then, 2,200 questionnaires were distributed to the research sample, 1985 of which were returned to the researcher (90.23\%). By removing incomplete questionnaires, 1,940 questionnaires were identified to be appropriate for analysis. To analyze the data, descriptive statistical methods (tables, percentages, and total percentages) were used.

\section{Results and Discussion}

The results showed that the prevalence rate of violence involvement was $4.1 \%$, doping $3 \%$, alcohol use $2.5 \%$, shisha use $2 \%$, cigarette use $0.3 \%$, and illicit drug use $0.3 \%$ among professional athletes (Table 1). The prevalence of HRBs in different sports is shown in Table 2.

The primary purpose of our study was to examine the prevalence of HRBs in Iranian professional athletes and determine the prevalence of HRBs among athletes of the team and individual sports. According to the results, the prevalence of violence involvement was $4.1 \%$, doping $3 \%$, alcohol use $2.5 \%$, shisha use $2 \%$, cigarette use $0.3 \%$, and illicit drug use $0.3 \%$ among professional athletes. Little studies have been done on HRBs in professional athletes, showing that the prevalence rate of HRBs in professional athletes is low. For example, concerning smoking, the results of this study are in line with those of Hessami et al. (2012) that showed the rate of smoking was lower among professional athletes than in the general population (14). Chaabane et al. (2016) also showed the prevalence of tobacco use was 27.7\% among 108 male professional athletes (12). Another study showed a small percentage of Iranian professional athletes (3\%) did doping. Although the use of performanceenhancing substances is not a new sporting phenomenon (15) and professional athletes use drugs for some acceptable reasons (11), sometimes, the pressure of sports competitions and winning at all costs inspire the professional athletes to do doping. Playing to win at all costs may lead an athlete to cheat to reach his/her goal (16). The win-atall-costs approach may lead athletes to sacrifice all for the cause (17). Some drug abuse occurs, such as alcohol or marijuana, without the intent of performance enhancement (11). In this regard, the study results showed that $2.5 \%$ of the research sample drunk alcohol and $0.3 \%$ used illicit drugs.

Overall, the research findings suggested that the prevalence rate of HRBs in Iranian professional athletes was relatively low. According to the literature, structured time schedules, supervision, and frequent exposure to normative behaviors associated with health benefits, development of group identities and cultures, and providing supervision and monitoring (18) due to participation in sports can lead to less engagement in HRBs. According to Leonard (1995), participation in various facets of physical activity is typically thought of as a deterrent to various manifestations of delinquent behavior (19). Moreover, sports participation at the professional-level may generate greater public expectations of athletes as role models that they do not engage in a given HRB. When professional athletics as sports participants become aware that their behaviors come to the attention of the social audience, it reduces the risk of further deviance due to the consequences of stigmatization (7). On the other hand, risk-taking behavior is associated with an individual's personality characteristics (20) and such personality characteristics may prevent engaging in HRBs. Therefore, public health decisionmakers and sports decision-makers should make careful 


\begin{tabular}{|c|c|c|c|c|c|c|c|c|}
\hline \multirow{2}{*}{ High-risk behavior } & \multicolumn{8}{|c|}{ Have You Ever Been Warned for The Following? } \\
\hline & \multicolumn{4}{|c|}{ Yes, No. (\%) } & \multicolumn{4}{|c|}{ No, No. (\%) } \\
\hline Doping & \multicolumn{3}{|c|}{$58(3)$} & & \multicolumn{4}{|c|}{$1882(97)$} \\
\hline Cigarette use & \multicolumn{3}{|c|}{$6(0.3)$} & & \multicolumn{4}{|c|}{1934 (99.7) } \\
\hline Shisha use & \multicolumn{3}{|c|}{$39(2)$} & & \multicolumn{4}{|c|}{$1901(98)$} \\
\hline Alcohol use & \multicolumn{3}{|c|}{$49(2.5)$} & & \multicolumn{4}{|c|}{$1891(97.5)$} \\
\hline Violence involvement & \multicolumn{3}{|c|}{$80(4.1)$} & & \multicolumn{4}{|c|}{$1860(95.9)$} \\
\hline fighting with spectators & \multicolumn{3}{|c|}{$58(3)$} & & \multicolumn{4}{|c|}{$1882(97)$} \\
\hline fighting with coach & \multicolumn{3}{|c|}{$78(4)$} & & \multicolumn{4}{|c|}{$1862(96)$} \\
\hline fighting with referee & \multicolumn{3}{|c|}{$107(5.5)$} & & \multicolumn{4}{|c|}{$1833(94.5)$} \\
\hline fighting with opponent & \multicolumn{3}{|c|}{$97(5)$} & & \multicolumn{4}{|c|}{$1843(95)$} \\
\hline fighting with teammate & \multicolumn{3}{|c|}{$58(3)$} & & \multicolumn{4}{|c|}{$1882(97)$} \\
\hline Illicit drug use & \multicolumn{3}{|c|}{$6(0.3)$} & & \multicolumn{4}{|c|}{$1934(99.7)$} \\
\hline \multirow{2}{*}{ HRBs } & \multicolumn{8}{|c|}{ Sports } \\
\hline & Soccer & Volleyball & Basketball & Handball & Wrestling & Taekwondo & Karate & Weightlifting \\
\hline Doping & 18 & 5 & 5 & 7 & 7 & 3 & 4 & 2 \\
\hline Cigarette use & 1 & 1 & 0 & 3 & 0 & 0 & 1 & 0 \\
\hline Shisha use & 12 & 7 & 4 & 4 & 5 & 2 & 1 & 4 \\
\hline Alcohol use & 23 & 4 & 3 & 10 & 3 & 1 & 2 & 3 \\
\hline Violence involvement & 27 & 14 & 11 & 8 & 7 & 4 & 6 & 3 \\
\hline Illicit drug use & 2 & 1 & 1 & 1 & 0 & 0 & 0 & 1 \\
\hline
\end{tabular}

decisions and take necessary efforts to increase participation in sports as a good solution for decreasing the prevalence of high-risk behaviors. Moreover, the education of behavior's values and standards needs to be considered. However, using sports as a preventing factor for high-risk behaviors needs to have a proper foundation.

This study had several limitations that should be noted. First, the results are based on participants' selfreports of HRBs. In this study, it was assumed that all participants answered the research questions honestly; however, obtaining reliable information on some HRBs is difficult, and athletes are not willing to discuss these topics for some reason. This may cause the true rate of HRBs in the research sample not to be fully recognized. To guard against such problems, we emphasized the confidentiality of the data and notified the participants not to put their names on their surveys. Second, the findings of this research were obtained from Iranian professional athletes in some special sports. Therefore, caution should be taken when generalizing the findings to other professional athletes in other countries and other sports that were not as- sessed in our study. Third, in the study, the research sample consisted only of male athletes, and female athletes were not included.

\section{Acknowledgments}

The authors thank the study participants for their cooperation and the Basij Bases for distributing and gathering the questionnaires.

\section{Footnotes}

Authors' Contribution: Study concept and design: Ahmadali Asefi and Ali Ghanbari Barzian; Analysis and interpretation of data: Ahmadali Asefi and Ali Ghanbari Barzian; Drafting of the manuscript: Ahmadali Asefi; Critical revision of the manuscript for important intellectual content: Ahmadali Asefi and Ali Ghanbari Barzian; Statistical analysis: Ahmadali Asefi; Administrative, technical, and material support: Ahmadali Asefi and Ali Ghanbari 
Barzian; Study supervision: Ahmadali Asefi and Ali Ghanbari Barzian

Conflict of Interests: The authors declare that there is no conflict of interest in this study.

Funding/Support: The authors declare that this article did not have any financial support.

\section{References}

1. Diehl K, Thiel A, Zipfel S, Mayer J, Litaker DG, Schneider S. How healthy is the behavior of young athletes? A systematic literature review and meta-analyses. J Sports Sci Med. 2012;11(2):201-20. [PubMed: 24149192]. [PubMed Central: PMC3737871].

2. Bovard RS. Risk behaviors in high school and college sport. Curr Sports Med Rep. 2008;7(6):359-66. doi: 10.1249/JSR.ob013e31818fobed. [PubMed: 19005360].

3. Peretti-Watel P, Guagliardo V, Verger P, Pruvost J, Mignon P, Obadia Y. Risky behaviours among young elite-student-athletes. Int Rev Sociol Sport. 2016;39(2):233-44. doi: 10.1177/1012690204043467.

4. Kwan M, Bobko S, Faulkner G, Donnelly P, Cairney J. Sport participation and alcohol and illicit drug use in adolescents and young adults: a systematic review of longitudinal studies. Addict Behav. 2014;39(3):497-506. doi: 10.1016/j.addbeh.2013.11.006. [PubMed: 24290876].

5. Baumert PW, Henderson JM, Thompson NJ. Health risk behaviors of adolescent participants in organized sports. $J$ Adolesc Health. 1998;22(6):460-5. doi: 10.1016/s1054-139x(97)00242-5.

6. Johnson KE, Eisenberg ME, Bearinger LH, Fulkerson JA, Sieving RE. Relationships between sports team participation and health-risk behaviors among alternative high school students. Am J Health Educ. 2014;45(3):158-65. doi: 10.1080/19325037.2014.893852.

7. Eitle D, Turner R, Eitle TM. The deterrence hypothesis reexamined: Sports participation and substance use among young adults. J Drug Issues. 2016;33(1):193-221. doi:10.1177/002204260303300108.

8. Rockafellow BD, Saules KK. Substance use by college students: the role of intrinsic versus extrinsic motivation for athletic involvement. Psychol Addict Behav. 2006;20(3):279-87. doi: 10.1037/0893-164X.20.3.279. [PubMed: 16938065].
9. Ford JA. Substance use among college athletes: a comparison based on sport/team affiliation. J Am Coll Health. 2007;55(6):367-73. doi: 10.3200/JACH.55.6.367-373. [PubMed: 17517549].

10. Baron DA, Martin DM, Abol Magd S. Doping in sports and its spread to at-risk populations: an international review. World Psychiatry. 2007;6(2):118-23. [PubMed: 18235871]. [PubMed Central: PMC2219897].

11. Reardon CL, Creado S. Drug abuse in athletes. Subst Abuse Rehabil. 2014;5:95-105. doi: 10.2147/SAR.S53784. [PubMed: 25187752]. [PubMed Central: PMC4140700].

12. Chaabane Z, Murlasits Z, Mahfoud Z, Goebel R. Tobacco use and its health effects among professional athletes in Qatar. Can Respir J. 2016;2016:2684090. doi: 10.1155/2016/2684090. [PubMed: 28025593] [PubMed Central: PMC5153470 financial or personal or other relationships that could influence their work].

13. Chen Y, Buggy C, Kelly S. Winning at all costs: a review of risk-taking behaviour and sporting injury from an occupational safety and health perspective. Sports Med Open. 2019;5(1):15. doi: 10.1186/s40798019-0189-9. [PubMed: 31049736]. [PubMed Central: PMC6497707].

14. Hessami Z, Aryanpur M, Emami H, Masjedi M. Behavior and knowledge of Iranian professional athletes towards smoking. Asian J Sports Med. 2012;3(4):297-300. doi: 10.5812/asjsm.34603. [PubMed: 23342230]. [PubMed Central: PMC3525828].

15. Bloodworth A, McNamee M. Clean olympians? Doping and antidoping: The views of talented young British athletes. Int J Drug Policy. 2010;21(4):276-82. doi: 10.1016/j.drugpo.2009.11.009. [PubMed: 20056401].

16. Vallerand RJ, Losier GF. Research.J Sport Exerc Psychol. 1994;16(3):22945. doi: $10.1123 /$ jsep.16.3.229.

17. Rudd A, Mondello MJ. How do college coaches define character? A qualitative study with division IA head coaches. J Coll Char. 2006;7(3) doi: 10.2202/1940-1639.1524.

18. Pate RR, Trost SG, Levin S, Dowda M. Sports participation and health-related behaviors among US youth. Arch Pediatr Adolesc Med. 2000;154(9):904-11. doi: 10.1001/archpedi.154.9.904. [PubMed: 10980794].

19. Leonard II WM. The influences of physical activity and theoretically relevant variables in the use of drugs: The deterrence hypothesis revisited. J Sport Behav. 1998;21(4):421.

20. Greene K, Krcmar M, Walters LH, Rubin DL, Hale L; Jerold. Targeting adolescent risk-taking behaviors: the contributions of egocentrism and sensation-seeking. J Adolesc. 2000;23(4):439-61. doi: 10.1006/jado.2000.0330. [PubMed:10936016]. 